\title{
Computational investigation of aerodynamic characteristics and drag reduction of a bus model
}

\author{
Eyad Amen Mohamed", Muhammad Naeem Radhwi, Ahmed Farouk Abdel Gawad \\ Mech. Eng. Dept., College of Eng. \& Islamic Archit., Umm Al-Qura Univ., Makkah, Saudi Arabia \\ Email address: \\ eytworld@gmail.com (E. A. Mohamed),mnradhwi@uqu.edu.sa (M. N. Radhwi), afaroukg@yahoo.com (A. F. A. Gawad)
}

\section{To cite this article:}

Eyad Amen Mohamed, Muhammad Naeem Radhwi, Ahmed Farouk Abdel Gawad. Computational Investigation of Aerodynamic Characteristics and Drag Reduction of a Bus Model. American Journal of Aerospace Engineering. Special Issue: Hands-on Learning Technique for Multidisciplinary Engineering Education. Vol. 2, No. 1-1, 2015, pp. 64-73. doi: 10.11648/j.ajae.s.2015020101.16

\begin{abstract}
It is well-known that buses comprise an important part of mass transportation and that there are many types of buses. At present, the bus transportation is cheaper and easier to use than other means of transportation. However, buses have some disadvantages such as air pollution due to engine exhaust. This study is an attempt to reduce the gas emissions from buses by reducing the aerodynamic drag. Several ideas were applied to achieve this goal including slight modification of the outer shape of the bus. Thus, six different cases were investigated. A computational model was developed to conduct this study. It was found that reduction in aerodynamic drag up to $14 \%$ can be reached, which corresponds to $8.4 \%$ reduction in fuel consumption. Also, Neuro-Fuzzy technique was used to predict the aerodynamic drag of the bus in different cases.
\end{abstract}

Keywords: Computational Investigation, Aerodynamic Characteristics, Drag Reduction, Bus Model

\section{Introduction}

\subsection{Background}

Nowadays, the waste of energy and the environmental pollution are some of the major global concerns for all science disciplines especially engineering. There are a lot of researchers who studied the aerodynamic behavior around heavy vehicles and tried to control their harmful emissions. Thus, they considered how to find out a better way to improve the vehicle performance by modifying the shape and weight of the vehicle.

Buses are one type of the heavy vehicles that consume much fuel. They are road vehicles designed to carry passengers in different applications. Buses can have a capacity as high as 300 passengers. The most common type of buses is the single-decker rigid bus. The larger loads are carried by double-decker buses and articulated buses. The smaller loads are carried by midi-buses and minibuses. Coaches are used for longer distance services.

Bus manufacturing is increasingly globalised with the same design appearing around the world. Buses may be used for scheduled bus transport, scheduled coach transport, school transport, private hire, tourism, etc. Promotional buses may be used for political campaigns and others are privately operated for a wide range of purposes.
Historically, Horse-drawn buses were used from the 1820s, followed by steam buses in the 1830s, and electric trolleybuses in 1882. The first internal combustion engine buses were used in 1895 [1]. Recently, there has been growing interest in hybrid electric buses, fuel cell buses, electric buses as well as ones powered by compressed natural gas or bio-diesel.

\subsection{Previous Investigations}

Generally, there is somehow shortage in the investigations that consider aerodynamics of buses in comparison to other heavy vehicles, e.g., trucks.

Newland [1] aimed to develop a transit bus fuel consumption function based upon relationships found in the literature between bus fuel consumption and various bus operating characteristics especially their variable passenger loads.

Roy and Srinivasan [2] studied the aerodynamics of trucks and other high-sided vehicles that are of significant interest in reducing road accidents due to wind loading and in improving fuel economy. They concentrated on the associated drag due to the exterior rear-view mirrors. They stated that modifying truck geometry can reduce drag and improve fuel economy.

Diebler and Smoth [3] developed experimentally a ground research vehicle $(G R V)$ to study the base drag on large-scale vehicles at subsonic speeds. They concentrated on base drag 
of trucks, buses, motor homes, reentry vehicles, and other large-scale vehicles. They presented preliminary results of both the effort to formulate a new base drag model and the investigation into a method of reducing total drag by manipulating forebody drag.

Yamin [4] used computational fluid dynamics (CFD) technique to simulate external flow analysis of a coach. His results suggested that the steady state $C F D$ simulation can be used to boost the aerodynamic development of a coach.

Abdel Gawad and Abdel Aziz [5] investigated experimentally and numerically the effect of front shape of buses on the characteristics of the flow field and heat transfer from the rear of the bus in driving tunnels. Their study covered three bus models with flat-, inclined-, and curved-front shapes They found that the front shape of the bus affects its aerodynamic stability in driving tunnels. Also, they stated that the cooling of the inclined- and curved-front vehicles is better than the cooling of the flat-front bus by about $20 \%$.

François et al. [6] studied experimentally the aerodynamics characteristics and response of a double deck bus, which is a bus type very used in the Argentinean routes, submitted mainly to cross-wind. They measured pressure distributions over the frontal and lateral part of the bus and also drag and lateral forces related to the position of centre of gravity.

Yelmule and Kale [7] considered experimentally and numerically the aerodynamics of open-window buses where airflow due to motion provides comfort. They stated that an overall drag reduction of about $30 \%$ at $100 \mathrm{~km} / \mathrm{h}$ can be reached by modifying the bus exterior body.

Mohamed-Kassim and Filippone [8] analyzed the fuel-saving potentials of drag-reducing devices retrofitted on heavy vehicles. They considered realistic on-road operations by simulating typical driving routes on long-haul and urban distributions; variations in vehicle weight. Their results show that the performance of these aerodynamic devices depend both on their functions and how the vehicles are operated such that vehicles on long-haul routes generally save twice as much fuel as those driven in urban areas.

Patil [9] performed aerodynamic flow simulation on one of conventional bus to demonstrate the possibility of improving the performance with benefits of aerodynamic features around the bus by reducing drag, which improves the fuel consumption. They optimized one of the conventional bus models and tried to reduce drag by adding spoilers and panels at rear portion along with front face modification. Their results showed that drag can be decreased without altering the internal passenger space and by least investment.

Also, the issue of fuel consumption was covered by many authors [10] and [11].

\subsection{Present Investigation}

The present study focuses on the aerodynamic characteristics of buses especially drag, either form or friction, which influences directly the fuel consumption.

A computational model was developed using the commercial code ANSYS-Fluent 13 to predict the aerodynamic performance of buses.
Modifications of the external body and/or surface of the bus to reduce the aerodynamic drag are proposed. The authors carefully considered that the proposed modifications do not affect the safety and operation of the bus. Also, the modifications do not change the main body/structure of the bus. Actually, modifications can be applied with considerably low cost and fairly technical skills.

The computations were carried out for different values of Reynolds number.

\section{Governing Equations and Turbulence Modeling}

\subsection{Governing Equations}

The equations that govern the fluid flow around a model are time-averaged continuity and momentum equations which, for the steady, incompressible flow, are given by, respectively:

$$
\begin{gathered}
\frac{\partial U_{i}}{\partial x_{i}}=0 \quad \mathrm{i}=1,2,3 \\
\mathrm{U}_{\mathrm{j}} \frac{\partial \mathrm{U}_{\mathrm{i}}}{\partial \mathrm{x}_{\mathrm{j}}}=\frac{\partial}{\partial \mathrm{x}_{\mathrm{j}}}\left(\mathrm{v} \frac{\partial \mathrm{U}_{\mathrm{i}}}{\partial \mathrm{x}_{\mathrm{j}}}-\overline{\mathrm{u}_{\mathrm{l}} \mathrm{u}_{\mathrm{j}}}\right)-\frac{1}{\rho} \frac{\partial \mathrm{P}}{\partial \mathrm{x}_{\mathrm{i}}} \quad i, j=1,2,3 .
\end{gathered}
$$

In the above, $U_{i}$ is the mean-velocity vector with components $U, V$ and $W$ in $x, y$ and $z$ directions, respectively, $P$ is the static pressure, $\rho$ is the fluid density and $\nu$ is its kinematic viscosity. Repeated indices imply summation. The turbulence model involves calculation of the individual Reynolds stresses $\left(\overline{u_{\imath} u_{\jmath}}\right)$ using transport equations. The individual Reynolds stresses are then used to obtain closure of the Reynolds-averaged momentum equation (Eq. 2).

\subsection{Turbulence Modeling (Realizable $k-\varepsilon$ Turbulence Model)}

The realizable $k-\varepsilon$ turbulence model was used in the present study. The realizable $k-\varepsilon$ model differs from the standard $k$ - $\varepsilon$ model in two important ways:

- The realizable $\boldsymbol{k}-\varepsilon$ model contains an alternative formulation for the turbulent viscosity.

- A modified transport equation for the dissipation rate, $\varepsilon$, has been derived from an exact equation for the transport of the mean-square vorticity fluctuation.

For further details about the realizable $k-\varepsilon$ turbulence model, one may refer to [12].

\subsection{Drag Calculations}

The results focus on the drag coefficient, i.e., pressure (form), friction, and total drag coefficients.

\subsubsection{Pressure (form) Drag}

The coefficient of pressure drag, $C_{D_{p}}$, is calculated by Eq. 3 as follows,

$$
C_{D_{p}}=\frac{\Delta P}{\left(0.5 \times \rho \times U_{\infty}^{2}\right)}
$$

Then, the force of pressure drag is calculated as 


$$
D_{p}=C_{D_{p}} \times 0.5 \times \rho \times U_{\infty}^{2} \times A_{F}
$$

Where, $D_{p}$ is the drag force due to pressure, $A_{F}$ is the frontal (projected) area of the bus $=H \times W, \rho$ is the flow density, $U_{\infty}$ is the bus speed, and $\Delta P$ is the pressure difference between the front and rear surfaces of the bus.

\subsubsection{Friction Drag}

The force of friction drag is calculated for the two side surfaces and roof of the bus using the following equation:

$$
D_{f}=C_{D_{f}} \times \frac{1}{2} \rho \times U_{\infty}^{2} * A_{R S}
$$

Where, $C_{D_{f}}$ is the coefficient of friction drag, $A_{R S}$ is the area summation of roof and side surfaces $=A_{R}+A_{S}, A_{R}$ is the roof area $=L \times W$, and $A_{S}$ is the side surfaces $=2 \times L \times H$.

Generally, the actual operating Reynolds number $\left(R e=U_{\infty}\right.$ $L / v)$ is greater than the critical Reynolds number $\left(R e_{c r}=5 \times\right.$ $10^{5}$ for a flat surface) for all test cases, which means the flow is turbulent. Thus, the coefficient of friction drag is calculated as [13]:

$$
C_{D f}=\frac{0.031}{R e_{L}^{\frac{1}{7}}}
$$

Where, $L$ is the bus length and $v$ is the flow kinematic viscosity.

\subsubsection{Total Drag}

The value of the total drag force, $D_{T}$, is calculated as:

$$
D_{T}=D_{p}+D_{f}
$$

Then, the coefficient of total drag, $C_{D_{T}}$, is calculated as:

$$
C_{D_{T}}=\frac{\mathrm{D}_{\mathrm{T}}}{\left(0.5 \times \rho \times U_{\infty}^{2}\right) A_{F}}
$$

\section{Original and Modified Models}

The original model represents an actual bus that was produced by Mercedes Benz, Type: Coach Travego M [14], Fig. 1.

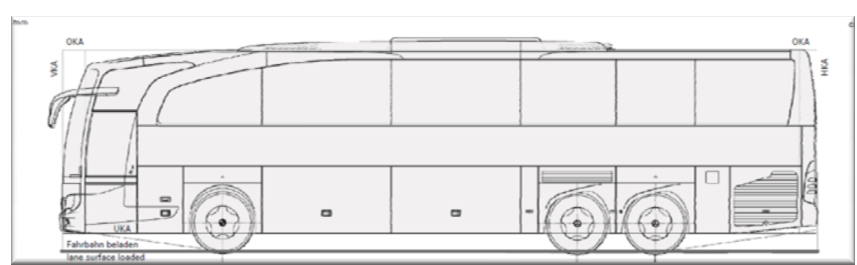

Figure 1. Side view of the bus [14].

This original model is considered as the comparing reference of the present study. The total length of the bus is $13 \mathrm{~m}$, the width is $2.55 \mathrm{~m}$, and the height is $3.1567 \mathrm{~m}$ as shown in Fig. 1. The fuel tank capacity is about 475 litres.

Some modifications were proposed to the original model. Each modification produced a new model. A specific name was given to each new model for classification. Table 1 shows the names and shapes of the different models.
Table 1. Names and shapes of the different models

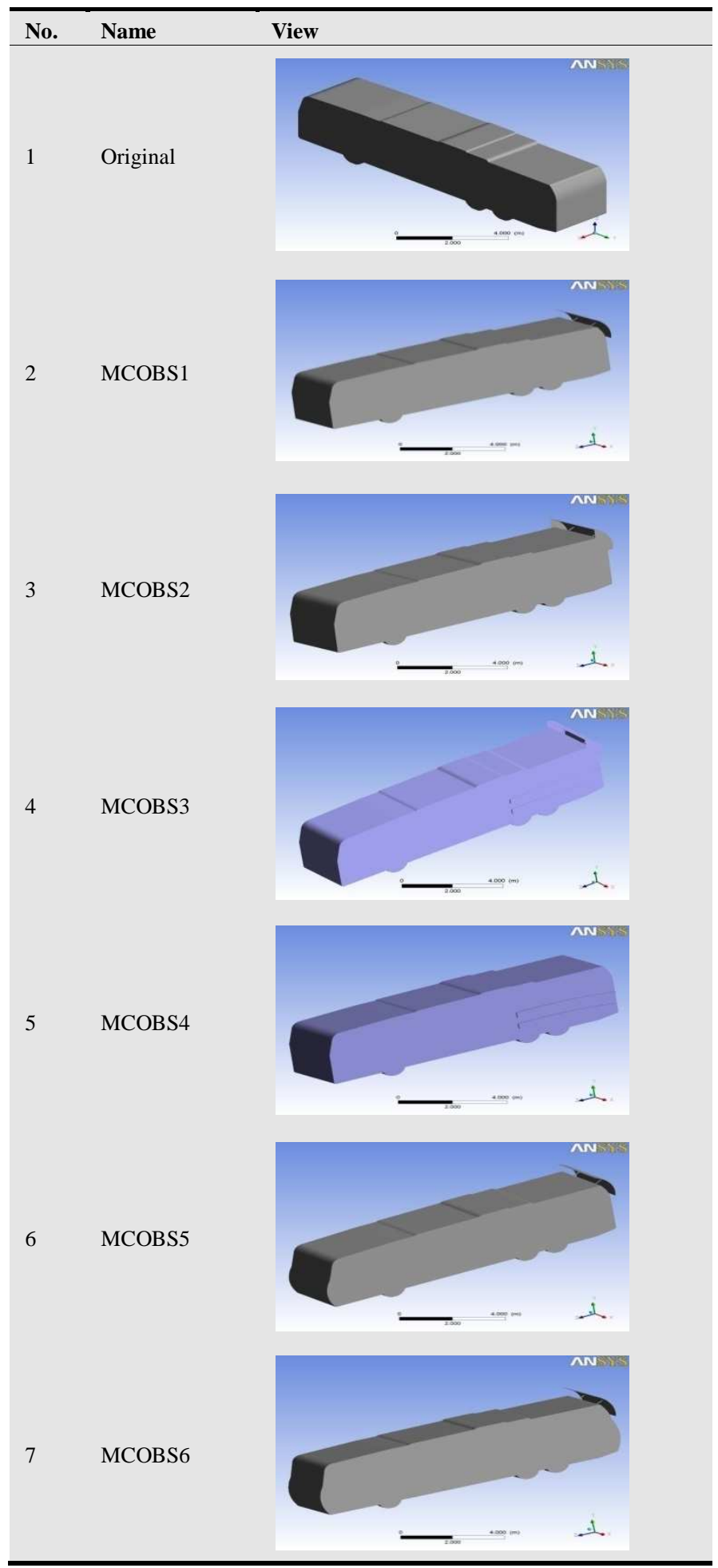

The names and shapes that appear in table 1 can be explained as follows:

Original: It is the actual shape of the bus without modifications.

MCOBS1: A curved device is added at the rear of the bus to direct the air flow downward directly behind the bus. It has two supports.

MCOBS2: Similar to MCOBS1 with closing the two left 
and right ends of the curved device to grantee that all air is directed downward without side escape.

MCOBS3: The bus is equipped with the same device of MCOBS2. Also, two small ducts $(4500 \times 50 \times 300 \mathrm{~mm})$ are added on both sides of the bus to drive air, with relatively high pressure, to the low-pressure zone behind the bus.

MCOBS4: Only two small ducts are added on both sides of the bus. There is no curved device.

MCOBS5: The bus is equipped with a curved device similar to MCOBS1. The front surface of the bus is modified to have a suitable curvature.

MCOBS6: Similar to MCOBS5 but the rear surface has also a curvature similar to the one of the front surface.

\section{Computational Aspects}

\subsection{Tested Velocities}

The computations were mainly carried out at $100 \mathrm{~km} / \mathrm{h}$ $(27.22 \mathrm{~m} / \mathrm{s})$ for all cases. However, to evaluate the effect of bus velocity on the aerodynamic characteristics and drag, other three values of velocity were examined for the case of MCOBS5. Table 2 shows the four values of velocity and the corresponding values of Reynolds number.

Table 2. Tested bus velocities.

\begin{tabular}{llll}
\hline NO. & Speed $(\boldsymbol{K} \boldsymbol{m} / \boldsymbol{h})$ & Speed $(\boldsymbol{m} / \mathbf{s})$ & Reynolds number \\
\hline 1 & 70 & 19.44 & $16.73 \times 10^{6}$ \\
2 & 100 & 27.22 & $23.9 \times 10^{6}$ \\
3 & 120 & 33.33 & $28.68 \times 10^{6}$ \\
4 & 150 & 41.66 & $35.85 \times 10^{6}$ \\
\hline
\end{tabular}

\subsection{Computational Domain and Boundary Conditions}

As seen in Figure 2, the computational domain is a rectangle that contains the bus. The dimensions of the domain were selected to ensure free development of the air flow around the bus.

The boundary conditions of the domain can be listed as: $(i)$ Uniform velocity at the inlet surface. (ii) Zero pressure-gradient at the outlet surface. (iii) Solid condition at the ground, i.e., the surface below the bus. (iv) Symmetry condition at the two side surfaces and the top surface of the domain.

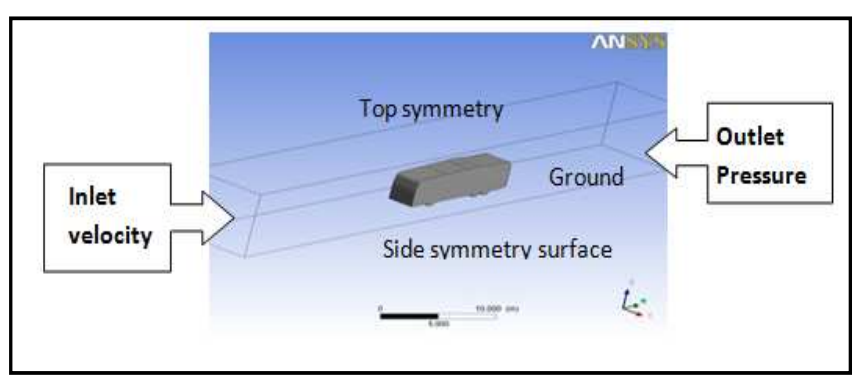

Figure 2. Computational domain and boundary conditions.

\subsection{Computational Grid (Mesh)}

The computational domain was discretized using unstructured grids. This type of grids usually guarantees the flexibility of generating enough computational points in locations of severe gradients. The computational domain was covered with tetrahedral elements (Figure 3). The grid is very fine next to the solid boundary. The dimensionless distance between the wall and first computational point is $y^{+} \approx 1.8$, which is calculated as

$$
y^{+}=\frac{u_{\tau} y}{v}
$$

Where, $y$ is the distance to the first point off the wall, $v$ is the kinematic viscosity, $u_{\tau}$ is the friction velocity.

$u_{\tau}=\sqrt{\frac{\tau}{\rho}}, \tau$ is the wall shear stress and $\rho$ is the flow density. The value of $y^{+} \approx 1.8$ ensures good resolution of the complex turbulent flow.

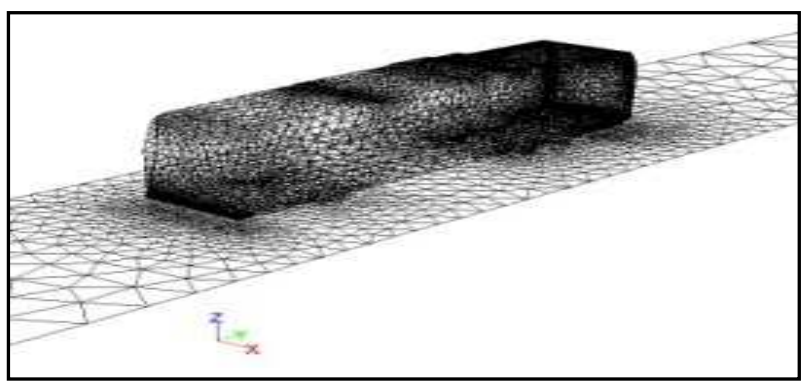

(a) Grid structure for "Original" shape.

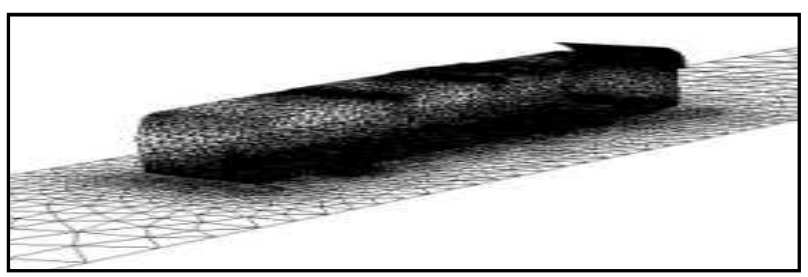

(b) Grid structure for MCOBS1

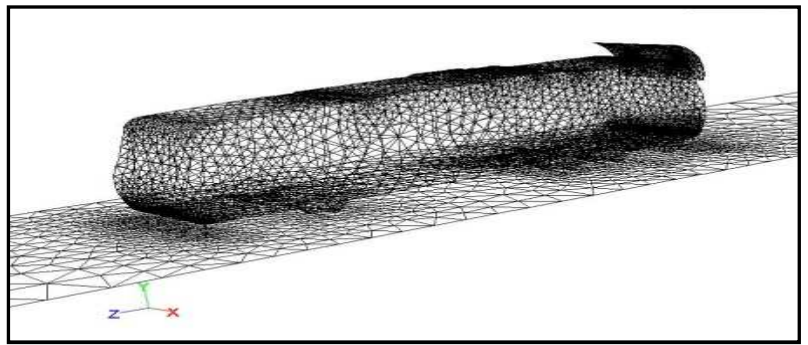

(c) Grid structure for MCOBS6.

Figure 3. Samples of grid structures.

\subsection{Grid Independency}

Careful consideration was paid to ensure the grid-independency of the computational results. Therefore, three grid sizes were used to test the grid-independency, namely: 50,000, 65,000 and 85,000 elements (cells).

Considering the flow characteristics, it was noticed that the 
difference between the results of the second and third grids is in the range of $2-3 \%$. Thus, the second grid size $(65,000)$ was used for all test cases.

\subsection{Numerical Scheme}

SIMPLE algorithm (Semi-Implicit Method for Pressure-Linked Equations) was used to solve the velocity and pressure fields. Each momentum equation was solved by the ", first-order upwind" scheme.

The "standard wall function" was used as the near-wall technique in the turbulence model. The solution continues until the numerical error of all computed quantities gets below $10^{-5}$.

\subsection{Validation of the Present Computational Algorithm}

The present numerical result of the total drag coefficient $C_{D_{T}}=0.698$ for the "original" compares very well to the range of 0.6-0.8 that was reported in [13]. The present value of $C_{D_{T}}$ lies exactly in the middle of the range. This gives confidence in the present computational scheme.

\section{Results and Discussions}

This section shows the computational results of the different considered cases (Original and modified models) that were mentioned in Sec.3. The main objective is to find the modified model that gives maximum drag reduction. However, the flow field (pressure and velocity) around the bus model is illustrated.

\subsection{Investigated Cases}

As it is well-known, the pressure (form) drag represents the major part of the total drag on bus in comparison to the friction drag, the pressure distributions on the frontal and rear surfaces are considered. The pressure drag depends on the difference between the pressure distributions on the frontal and rear surfaces of the bus. Figures 4 and 5 illustrate the pressure contours on the frontal and rear surfaces of the bus, respectively, for all cases.

The velocity field in the zone adjacent to the rear surface affects the pressure distribution on rear surface. Thus, velocity vectors, in a vertical section, are shown in Figure 6 for all cases. The vertical section passes through the mid-section of the bus width.

The results of various cases are discussed as follows:

\subsubsection{Original}

As expected, Figures 4 and 5 show that the pressure is really high on the bus frontal surface due to flow stagnation. The pressure is very low on the rear surface due to wake formation behind the bus. Figure 6 shows that two main vortices are formed in the wake zone behind the bus. The two vortices have nearly equal size. For this case, at $R e=23.9 \times 10^{6}$, the total drag coefficient $\left(C_{D_{T}}\right)$ equals 0.698 .

\subsection{2. $M c o b s 1$}

As can be seen in Figure 5, the curved-surface device at the rear of the bus reduces slightly the pressure on the rear surface in comparison to the "Original ". However, this change of pressure does not considerably reflect on the value of $C_{D_{T}}$ that becomes 0.649 .

Another effect of the curved-surface device is seen in Figure 6. The upper vortex behind the bus becomes smaller then the lower vortex. The curved-surface device directed the flow from the top surface at the bus to the wake zone behind the bus.

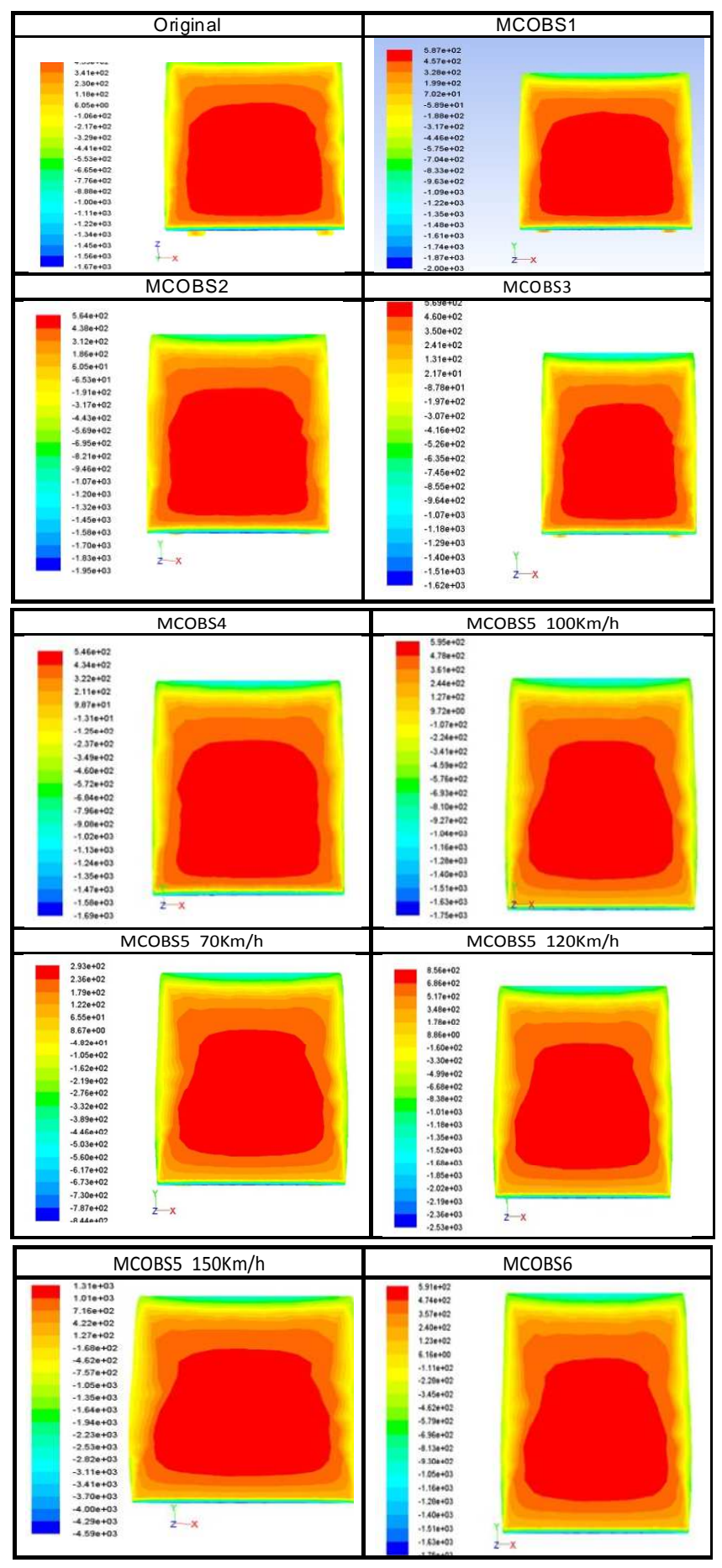

Figure 4. Pressure contours on the frontal surface. 

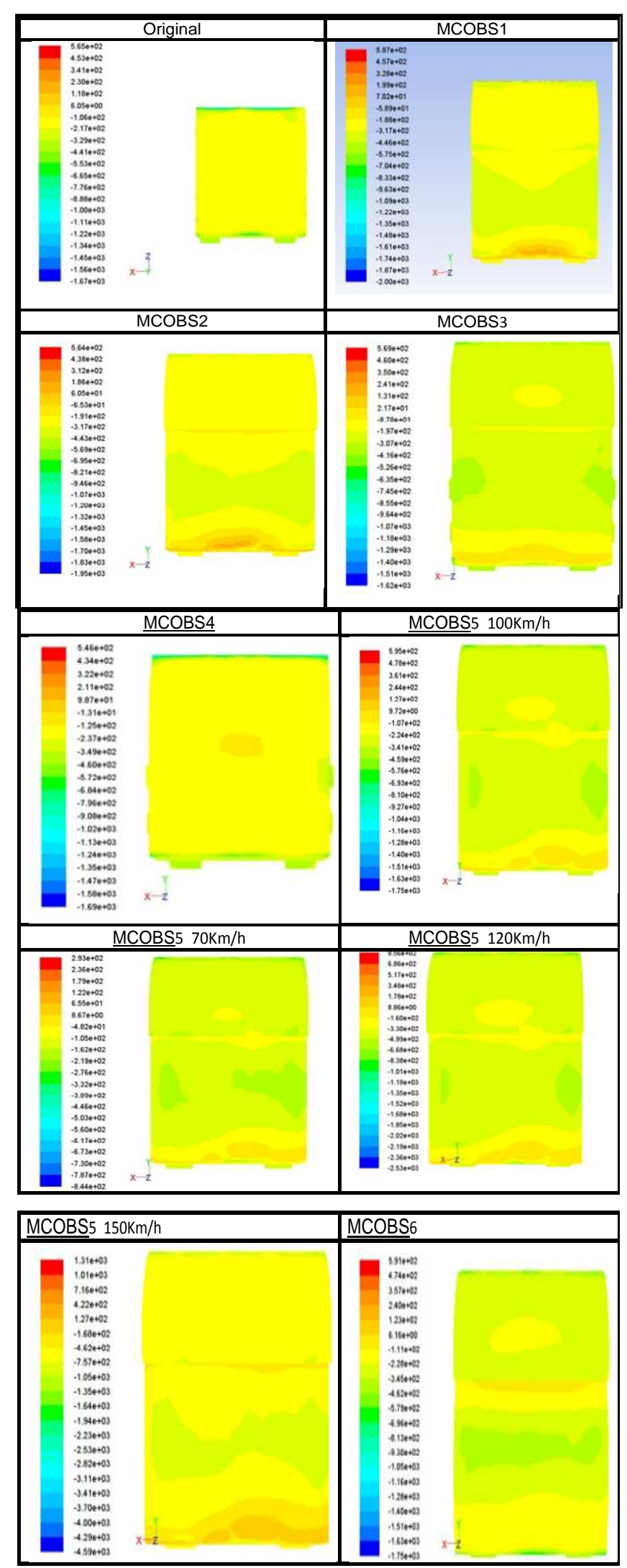

Figure 5. Pressure contours on the rear surface.

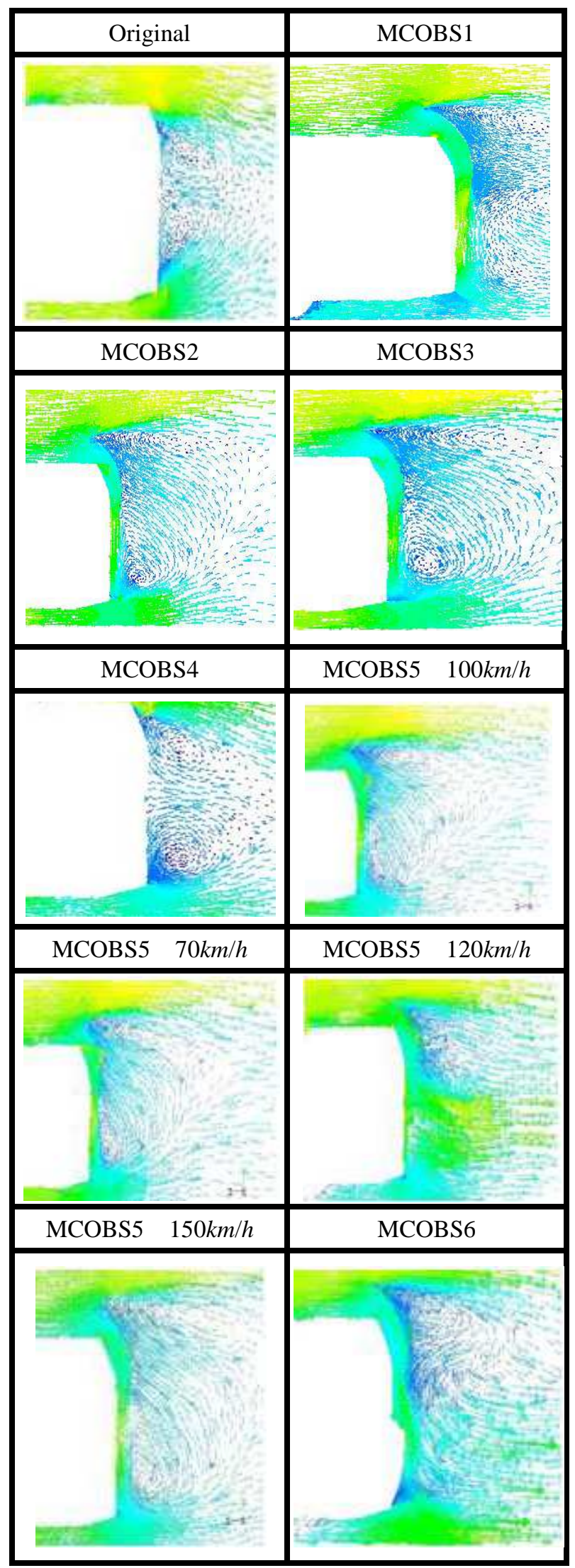

Figure 6. Velocity vectors behind the bus in a vertical section.

\subsubsection{Mcobs2}

It seems that the closed ends of the curved-surface device 
have a minor effect on the pressure distributions, Figure 5. In Figure 6, the vortices behind the bus are altered in comparison to MCOBS1. The value of $C_{D_{T}}$ is 0.652 , which is very close to that of MCOBS 2. Thus, the curved-surface device reduces the value at $C_{D_{T}}$ in comparison to the "Original".

\subsubsection{Mcobs3}

It seems that the two side ducts have a negative effect to the curved-surface device. They do not help in reducing the total drag on the bus. Unfortunately, they increase the value of $C_{D_{T}}$ to reach 0.691 , which is greater than the two values of MCOBS1 $\left(C_{D_{T}}=0.649\right)$ and MCOBS2 ( $\left.C_{D_{T}}=0.652\right)$. However, it is slightly lower than the value at the "original" $\left(C_{D_{T}}=0.698\right)$.

This may be attributed to the long path of the ducts, which causes big pressure drop inside them. Thus, air may be ever sucked inside them at their rear ends causing increase in the value of $C_{D_{T}}$. Generally, it is clear from Figure 6 that there is almost no change in comparison to MCOBS2.

\subsubsection{Mcobs4}

It is obvious that the two ducts alone have no effect in reducing the total drag on the bus. The value at $C_{D_{T}}$ is 0.697 , which is the same as the "Original" $\left(C_{D_{T}}=0.698\right)$. However, the two ducts cause the lower vortex behind the bus to extend downstream, Figure 6.

\subsubsection{Mcobs5}

It is found that the curvature at the frontal surface causes a noticeable change on the total drag on the bus. Thus, the value of $C_{D_{T}}$ becomes 0.632 for $100 \mathrm{~km} / \mathrm{h}$. This value is lower than that of the "Original" $\left(C_{D_{T}}=0.698\right)$.

In Figure 6, as expected, the curvature at the frontal surface has no effect on two vortices in the wake region behind the bus.

\subsubsection{Mcobs6}

It is obvious that the curvatures of the frontal and rear surfaces cause a remarkable change on pressures of these two surfaces, Figures 4 and 5. Thus, the value of $C_{D_{T}}$ reduces to 0.602 .

This is the lowest value of $C_{D_{T}}$ achieved in all test cases. Also, the wake zone behind the bus is favorably changed as can be seem in Figure 6.

\subsection{Overall view of all cases}

Based on the results of the previous section, an overall view of all cases can be demonstrated. Table 3 illustrates overall results of the total drag coefficient $\left(C_{D_{T}}\right)$ for all cases. Also, Figure 7 shows the values of total drag coefficient $\left(C_{D_{T}}\right)$ for all cases. Moreover, table 3 illustrates the percentage reduction in total drag coefficient for all cases of bus modifications.

It is clear from Table 3 and Figure 7 that the lowest value of $C_{D_{T}}=0.602$, which corresponds a total drag reduction of $14 \%$, is obtained for case MSCOBS6. This is the case of modifying the frontal and rear surfaces by slight curvature. This is the best case.

Whereas, the worst case is MCOBS4 with $C_{D_{T}}=0.697$ and total drag reduction of $0.14 \%$.
Thus, the idea of putting two side ducts seems useless. This is may be attributed to the relatively big length of the ducts. Internal friction at the walls of the ducts causes considerable pressure loss inside them. Thus, there is no pressure rise by the end of the ducts at the rear surface of the bus.

Table 3. Overall results of $C_{D_{T}}$.

\begin{tabular}{lllllll}
\hline No. & Case & $\begin{array}{l}\text { Velocity } \\
(\mathbf{k m} / \mathbf{h})\end{array}$ & $\begin{array}{l}\boldsymbol{R e} \\
\times \mathbf{1 0}^{\mathbf{6}}\end{array}$ & $C_{D_{T}}$ & $\begin{array}{l}C_{D_{T}} \\
\text { Reductio } \\
\mathbf{n}(\boldsymbol{\%})\end{array}$ & $\begin{array}{l}\text { Fuel } \\
\text { Reductio } \\
\mathbf{n}(\boldsymbol{\%})\end{array}$ \\
\hline 1 & Original & 100 & 23.9 & 0.698 & ---- & ---- \\
2 & MCOBS1 & 100 & 23.9 & 0.649 & 7 & 4.2 \\
3 & MCOBS2 & 100 & 23.9 & 0.652 & 6.6 & 4 \\
4 & MCOBS3 & 100 & 23.9 & 0.691 & 1 & 0.6 \\
5 & MCOBS4 & 100 & 23.9 & 0.697 & 0.14 & 0.1 \\
6 & MCOBS5 & 100 & 23.9 & 0.632 & 9.5 & 5.7 \\
7 & MCOBS5 & 70 & 16.73 & 1.03 & 47.6 & ---- \\
8 & MCOBS5 & 120 & 28.68 & 0.558 & 20 & 12 \\
9 & MCOBS5 & 150 & 35.85 & 0.428 & 38.7 & 23.2 \\
10 & MCOBS6 & 100 & 23.9 & 0.602 & 14 & 8.4 \\
\hline
\end{tabular}

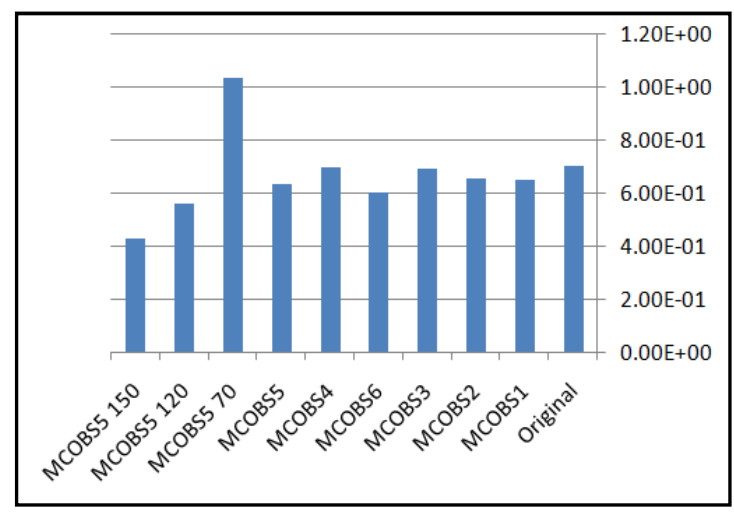

Figure 7. Values of total drag coefficient $\left(C_{D_{T}}\right)$ for all cases.

Table 4. An example of fuel saving

\begin{tabular}{llll}
\hline $\begin{array}{l}\text { Fuel consumption } \\
\text { of 'Original" } \\
(\text { Liter/h) }\end{array}$ & $\begin{array}{l}\text { Percentage } \\
\text { fuel saving } \\
(\%) \text { MOCBS6 }\end{array}$ & $\begin{array}{l}\text { Fuel consumption } \\
\text { of MOCBS6 }\end{array}$ & $\begin{array}{l}\text { Fuel saving } \\
(\text { Liter/h })\end{array}$ \\
\hline 66.88 & 8.4 & 61.26 & MOCBS6 \\
\hline
\end{tabular}

Also, Table 3 indicates that a considerable drag reduction up to $38.7 \%$, at $150 \mathrm{~km} / \mathrm{h}$, can be reached by increasing the bus velocity. This drag reduction may be attributed to the separation delay or even prevention due to the high momentum of the air surrounding the bus.

Unfortunately, high velocities are not always practical due to traffic and safely considerations. In table 3, the fuel reduction percentage was calculated based on the approximate relationship that was derived from [15]:

Fuel reduction $\%=(3 / 5) \times$ Total drag reduction $\%$

Thus, considerable fuel reduction can be obtained such as case MCOBS6 (8.4\%). As an example of the saving of fuel consumption, based on the present findings, Table 4 shows the 
annual saving of an intercity bus that operates at an average velocity of $100 \mathrm{~km} / \mathrm{h}$.

\section{Adaptive Neuro-Fuzzy Inference System (ANFIS)}

\subsection{Introduction}

The Adaptive Neuro-Fuzzy Inference system (ANFIS) was used to predict the values of the pressure drag coefficient $C_{D_{T}}$ based on the obtained data from the computational investigation. A well-trained nruro-fuzzy scheme can perform the prediction successfully based on enough computational data. After training, this technique enables the prediction of new values of $C_{D_{T}}$ that were not predicted by the computational study. Application of ANFIS needs much less programming effort and computer run-time in comparison to traditional computational fluid dynamics $(C F D)$ techniques.

Fuzzy logic $(F L)$ is a form of many-valued logic, which deals with reasoning that is approximate rather than fixed and exact. Compared to traditional binary sets (where variables may take on true or false values), fuzzy logic variables may have a truth value that ranges in degree between 0 and 1 .

ANFIS is a kind of neural network that is based on Takagi-Sugeno fuzzy inference system. Since it integrates both neural networks and fuzzy logic principles, it has potential to capture the benefits of both in a single framework. Its inference system corresponds to a set of fuzzy $I F-T H E N$ rules that have learning capability to approximate nonlinear functions. Hence, ANFIS is considered to be a universal estimator.

For more details about ANFIS, one may refer to Refs. [16] and [17].

\subsection{Present ANFIS Model}

Table 5. Training data for all cases

\begin{tabular}{llll}
\hline \multirow{2}{*}{ Case } & Input & Output \\
\cline { 2 - 4 } & Code & $\begin{array}{l}\text { Reynolds } \\
\text { number }\end{array}$ & $\begin{array}{l}\text { Pressure drag } \\
\text { coefficient }\left(\boldsymbol{C}_{\boldsymbol{D}_{\boldsymbol{p}}}\right)\end{array}$ \\
\hline Original & 1 & $23.9 \times 10^{6}$ & 0.661 \\
MCOBS1 & 2 & $23.9 \times 10^{6}$ & 0.611 \\
MCOBS2 & 3 & $23.9 \times 10^{6}$ & 0.614 \\
MCOBS3 & 4 & $23.9 \times 10^{6}$ & 0.654 \\
MCOBS4 & 5 & $23.9 \times 10^{6}$ & 0.564 \\
MCOBS6 & 6 & $23.9 \times 10^{6}$ & 0.659 \\
MCOBS5 & 7 & $23.9 \times 10^{6}$ & 0.595 \\
MCOBS5-70 & 8 & $16.73 \times 10^{6}$ & 0.994 \\
MCOBS5-120 & 9 & $28.68 \times 10^{6}$ & 0.522 \\
MCOBS5-150 & 10 & $35.85 \times 10^{6}$ & 0.392 \\
\hline
\end{tabular}

ANFIS was constructed based on "Quadrangle prediction". The two input parameters to ANFIS are the bus case and the Reynolds number $(R e)$. The bus cases are coded as numbers,
Table 5

The output of ANFIS is the pressure drag coefficient $\left(C_{D_{p}}\right)$. Table 5 shows the training data for all cases.

Figures 8 and 9 illustrate the structure and output performance surface of $A N F I S$, respectively. Figure 9 explains the variation of the Quadrangle predictions with the two inputs (bus case and $R e$ ), which end up with convergence.

After the success in training ANFIS, new set of data, which was not seen before by the ANFIS, is introduced to predict output $\left(C_{D_{p}}\right)$.

Thus, the ability of ANFIS to predict correctly the values of $C_{D_{p}}$ as output is confirmed.

Table 6 shows the new set of input data and the corresponding predictions of output.

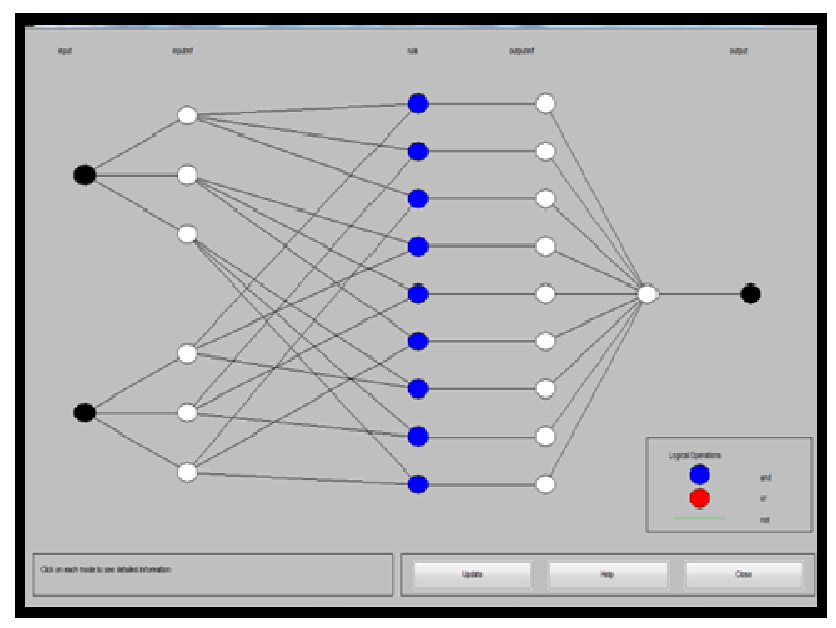

Figure 8. Structure of ANFIS model (Quadrangle Prediction).

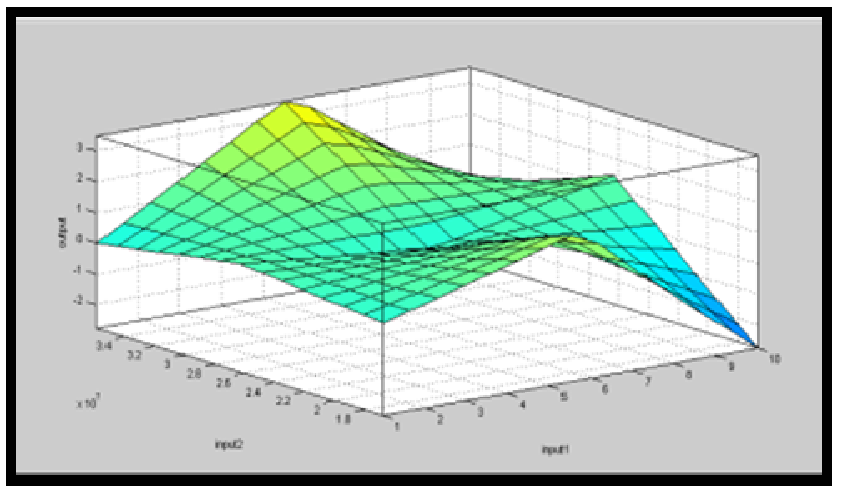

Figure 9. Output surface of performance of ANFIS model (Quadrangle Prediction).

Figure 10 represents validation of ANFIS new predictions. Comparison is made between the new predictions of ANFIS (Red) and the corresponding predictions of the present ANSYS-Fluent scheme (Blue) as CFD results.

Generally, it is clear that there is a fair agreement between ANFIS and CFD predictions. The differences between the two predictions may be attributed mainly to two reasons: (i) The small number of cases (10) that was used to train ANFIS. (ii) The generality of ANFIS that considered different cases of the bus with modifications. Better predictions are expected if 
ANFIS is modeled for each bus case with different values of $R e$.

However, Figure 10 suggests that ANFIS technique is promising if the above two points are carefully considered.

Table 6. Prediction of new data.

\begin{tabular}{lll}
\hline Input & Output \\
\hline Code & Reynolds number & $\begin{array}{l}\text { Pressure drag coefficient } \\
\left(\boldsymbol{C}_{\boldsymbol{D}_{\boldsymbol{p}}}\right)\end{array}$ \\
\hline 1 & $23.6 \times 10^{6}$ & 0.621 \\
2 & $20.1 \times 10^{6}$ & 0.64 \\
3 & $19.1 \times 10^{6}$ & 0.902 \\
4 & $22.4 \times 10^{6}$ & 0.794 \\
5 & $23.0 \times 10^{6}$ & 0.757 \\
6 & $18.7 \times 10^{6}$ & 1.45 \\
7 & $27.1 \times 10^{6}$ & 0.691 \\
\hline
\end{tabular}

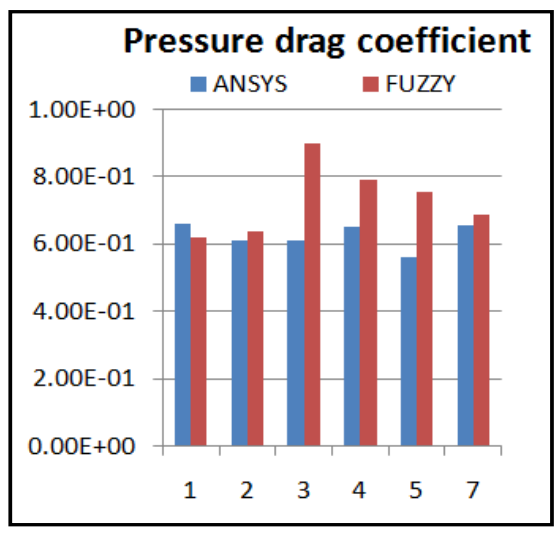

Figure 10. Validation of ANFIS new data.

\section{Conclusions}

A computational scheme was developed to study the possibility of drag reduction of buses. An actual bus was chosen to carry out the study. The values of the total drag coefficient $\left.\mathrm{C}_{(\mathrm{DT}}\right)$, corresponding to suggested modifications to the bus, were computed. Seven case studies were investigated and the reductions in total drag and fuel were recorded.

Based on the results and discussions of the previous sections, the following concluding points can be stated:

1. The curvature modification of the frontal and rear surfaces, case MCOBS6, gives the best drag reduction of $14 \%$. This gives a consequence fuel savings of about $8.4 \%$.

2. The proposed curvature at the frontal and rear surfaces is accepted from the economic and manufacturing points of view. This modification is easy to be implemented as it does not affect the body/structure of the bus.

3. The idea of adding a rear curved-shape device seems interesting. The present curved-shape causes a maximum drag reduction of $7 \%$, which corresponds to a fuel saving of about $4.2 \%$.Perhaps introducing other profiles of the curved-shape is a good idea to find the optimum profile that gives the highest drag reduction.

4. The using of side ducts proved to be inefficient technique. The idea of transferring high pressure from the upwind zone of the bus to its downwind zone to increase the pressure at the rear surface of the bus did not succeed. This may be attributed to the relatively big length of the ducts. Thus, internal friction causes losses and overall pressure drops in the ducts. So, the pressure at the rear surface of the bus is nearly the same as that of the bus wake.

5. The total drag on the bus decreases with the bus speed. However, the considerations of traffic and safety limit this option of increasing the bus speed.

6. Although the maximum value of fuel saving of $8.4 \%$ at $100 \mathrm{~km} / \mathrm{h}$ of the present study is not a big number, it represents a very good achievement when considering the huge amount of fuel consumption of buses allover the world, e.g., intercity buses.

7. Fairly good predictions were obtained from ANFIS. Increasing the amount of training data will certainly improve its efficiency.

8. Other ideas may be considered in future investigations such as:(i) air jets, using a suitable pneumatic system, may be injected from the rear surface of the bus to increase the pressure in the wake zone. (ii) Minimizing flow separation by tapering or rounding the fore-body of the bus, and modifying the roof of the bus.

\section{Nomenclature}

$A_{F} \quad$ : Frontal area.

$A_{S} \quad:$ Side area $=2 \times L \times H$.

$A_{R} \quad$ : Roof area $=L \times W$.

$A_{R S} \quad=A_{R}+A_{S}$.

$C_{D_{f}} \quad$ : Friction drag coefficient.

$C_{D_{p}} \quad$ : Pressure drag coefficient.

$C_{D_{T}} \quad$ : Total drag coefficient.

$C_{p} \quad$ : Pressure coefficient.

$D_{f} \quad$ : Frictions drag force $(N)$

$D_{p} \quad$ : Pressure drag force $(N)$.

$D_{T} \quad$ : Total drag force $(N)$.

$H \quad$ : Bus height.

$L \quad$ : Bus length.

$P \quad$ : Pressure $(k P a)$.

$P_{b} \quad:$ Outlet pressure $(k P a)$.

Re : Reynolds number.

$R e_{C r} \quad$ : Critical Reynolds number for flow on a flat plat.

$U_{\infty} \quad$ : Bus velocity.

$W \quad$ : Bus width.

$\Delta P \quad$ : Pressure difference. 


\section{Abbreviations}

$\begin{array}{ll}\text { ANFIS } & : \text { Adaptive Neuro-Fuzzy Inference system } \\ \text { CFD } & : \text { Computational fluid dynamics. } \\ F L & : \text { Fuzzy logic } \\ \text { GRV } & : \text { Ground research vehicle. } \\ \text { SIMPLE } & : \text { Semi-Implicit Method for Pressure-Linked } \\ & \text { Equations. }\end{array}$

\section{References}

[1] L. E. Newland, "A Fuel Consumption Function for Bus Transit Operations and Energy Contingency Planning", Technical Report: UM-HSRI-80-53, Highway Safety Research Institute, The University of Michigan, July 1980.

[2] S. Roy, and P. Srinivasan, "External Flow Analysis of a Truck for Drag Reduction", International Truck and Bus Meeting \& Exposition, Paper \#: 2000-01-3500, 2000.

[3] C. Diebler and M. Smith, "A Ground-Based Research Vehicle for Base Drag Studies at Subsonic Speeds", Technical Report: NASA/TM-2002-210737, NASA Dryden Flight Research Center, Edwards, California, November 2002.

[4] A. K. M. Yamin, "Aerodynamic Study of a Coach Using Computational Fluid Dynamic (CFD) Technique", M.Sc. in Automotive Engineering, Faculty of Engineering and Computing, Coventry University, August 2006.

[5] A. A. Abdel Aziz, and A. F. Abdel Gawad, "Aerodynamic and Heat Transfer Characteristics around Vehicles with Different Front Shapes in Driving Tunnels," Proceedings of Eighth International Congress of Fluid Dynamics \& Propulsion (ICFDP 8), December 14-17, 2006, Sharm El-Shiekh, Sinai, Egypt.

[6] D. G. François, J. S. Delnero, J. Colman, Di Leo J. Marañón and M. E. Camocardi, "Experimental determination of Stationary Aerodynamics loads on a double deck Bus", 11th Americas Conference on Wind Engineering, San Juan, Puerto Rico, June 22-26, 2009.
[7] M. M. Yelmule and S. R. Kale, "Aerodynamics of a Bus with Open Windows", Int. J. Heavy Vehicle Systems, Vol. 16, No. 4, 2009.

[8] Z. Mohamed-Kassim, A. Filippone, "Fuel savings on a heavy vehicle via aerodynamic drag reduction", Transportation Research Part D 15, 275-284, 2010.

[9] C. N. Patil, K.S. Shashishekar, A. K. Balasubramanian, and S. V. Subbaramaiah, "Aerodynamic Study and Drag Coefficient Optimization of Passenger Vehicle", International Journal of Engineering Research \& Technology (IJERT), Vol. 1, Issue 7, September-2012.

[10] Bob Lloyd, "Dissecting the Basic Fuel Consumption Equation into Its Components to Improve Adaptability to Changing Vehicle Characteristics", 25th ARRB Conference-Shaping the Future: Linking Policy, Research and Outcomes, Perth, Australia, 2012.

[11] I. M. Berry, "The Effects of Driving Style and Vehicle Performance on the Real-World Fuel Consumption of U.S. Light-Duty Vehicles", M.Sc. Mechanical Engineering and M.Sc. Technology and Policy, Massachusetts Institute of Technology, February 2010.

[12] Fluent guide manual, (2011).

[13] F. M. White, "Fluid Mechanics", McGraw-Hill, 7th Edition, 2008.

[14] Mercedes-Benz, Reisebus/Coach Travego M, Mannual. http://ebookbrowsee.net/1843659-graphics-travego-pdf-d9474 9039

[15] J. Patten, B. McAuliffe, W. Mayda, and B. Tanguay, "'Review of Aerodynamic Drag Reduction Devices for Heavy Trucks and Buses" NRC-CNRC Technical Report, Canada, 2012.

[16] Matlab guide manual, 2011.

[17] A. F. Abdel Gawad, "Computational and Neuro-Fuzzy Study of the Effect of Small Objects on the Flow and Thermal Fields of Bluff Bodies," Proceedings of 8th Biennial ASME conference on Engineering Systems Design and Analysis (ESDA2006), July 4-7, 2006, Torino, Italy. 